\title{
LAUDO TÉCNICO PERICIAL SOBRE INTERVENÇÃO AMBIENTAL IRREGULAR EM ÁREAS DE PRESERVAÇÃO PERMANENTE DE ZONA URBANA, ESTUDO DE UM CASO CONCRETO
}

\author{
HUGO FREDERICO SICKERT DE ALMEIDA ROCHA, \\ CRISTIANE PIRES SAMPAIO.
}

\begin{abstract}
RESUMO - O presente trabalho oferece o laudo técnico pericial realizado para apurar uma intervenção ambiental irregular em área sob regime especial de proteção, sendo ela definida pela legislação brasileira como área de preservação permanente (APP). Como forma de ilustrar as diversas faces e minúcias do trabalho técnico pericial, foi escolhido um cenário que apresenta como característica básica a supressão de vegetação em APP; Foram definidas as metodologias, os recursos tecnológicos, as análises realizadas e as possíveis ações para mitigação, compensação ou recuperação dos impactos causados aos recursos ambientais. Por tratar-se de caso real, os nomes, coordenadas geográficas e outros dados passíveis de identificar os envolvidos diretos serão alterados por pseudônimos e dados fictícios. Vale a ressalva que todas as informações contidas em um laudo técnico pericial são de domínio púbico e sujeitos a pesquisa por quem quer que seja; o cuidado na omissão dos dados visa, tão somente, a não exposição da figura de outrem.
\end{abstract}

PALAVRAS-CHAVE - Laudos periciais; Intervenção ambiental irregular; Supressão de vegetação; Recursos tecnológicos.

\section{INTRODUÇÃO}

A perícia ambiental no âmbito da justiça configura-se como uma ferramenta de fundamental importância no auxílio à tomada de decisão dos magistrados. Anos de dedicação aos estudos da legislação, suas minúcias e aplicabilidades são necessários para quem galga o cargo máximo de Juiz de Direito, o que lhes confere, com todo o mérito, o título popular de "doutor da lei".

Entretanto, seria ilusório imaginar que uma pessoa teria a capacidade de dominar, concomitantemente, as leis que regem uma nação e todos os atributos técnicos envolvidos em um caso. Como exemplo, espera-se de um Juiz que ele entenda todas as características atribuídas por lei para a definição de uma área de preservação permanente hídrica, mas não lhe pode ser cobrada capacidade técnica para realizar o geoprocessamento e fotointerpretação de imagens aéreas no intuito de alocar essas áreas no espaço físico.

A perícia ambiental é o trabalho técnico utilizado para analisar fatos correlacionados ao meio ambiente, definindo, quantificando e, quando necessário, valorando seus efeitos, normalmente negativos, dando respaldo à decisão final de promotores de justiça e juízes de direito, nas esferas civil e penal.

\section{CONTEXTO E APRESENTAÇÃO DO TRABALHO}

A Constituição Federal de 1988, em seu Artigo 225, define o meio ambiente como bem de uso comum do povo, sendo considerado essencial à sadia qualidade de vida. Confere, ainda, a responsabilidade quanto a sua preservação e defesa, não só ao Poder Público, mas à coletividade.

Art. 225 - Todos têm direito ao meio ambiente ecologicamente equilibrado, bem de uso comum do povo e essencial à sadia qualidade de vida, impondo-se ao Poder Público e à coletividade o dever de defendê-lo e preservá-lo para as presentes e futuras gerações (BRASIL, 1988).

Partindo dessa base fundamental, a legislação ambiental brasileira foi pautada e constitui hoje uma matéria extensa, amarrada, complexa, e, por vezes, controversa.

Neste cenário jurídico a presença de um profissional técnico se faz ainda mais necessária na elucidação das questões onde a interpretação do texto legal em si não seria suficiente para caracterizar a intervenção ou crime e, muito menos, seria capaz de definir suas características, magnitudes e respectivos valores.

A perícia ambiental apesar de ser uma matéria vasta e multidisciplinar ainda é pouco explorada pelos profissionais habilitados para sua execução. Por desconhecerem o ofício ou por receio da responsabilidade assumida no exercício dessa profissão, poucos são os que se aventuram nessa seara.

Dessa forma, o levantamento de modelos de Laudos Técnicos para estudos de caso fica restrito a duas opções: pesquisas públicas nos Tribunais de Justiça e secretarias do Ministério 
Público (que nem sempre são bem-vindas) e fazendo parte das redes de contato dos peritos atuantes.

O presente trabalho tem por finalidade suprir parte dessa demanda ao trazer para análise um caso de supressão de vegetação nativa em área de preservação permanente e seus desdobramentos.

O laudo será apresentado conforme foi protocolizado, porém seguindo a estrutura de tópicos deste texto.

As informações que pudessem caracterizar os envolvidos ou os locais intervencionados, foram alteradas para pseudônimos e dados fictícios, para não expor a figura de outrem.

Nesse mesmo sentido, alguns anexos foram ocultados.

\section{LAUDO TÉCNICO PERICIAL INTERVENÇÃO EM ÁREA DE PRESERVAÇÃO PERMANENTE DE CURSO DÁGUA ZONA URBANA}

\section{A. CONSIDERAÇÕES INICIAIS}

1) Objetivos da perícia

Avaliar os impactos ambientais provenientes de intervenção ambiental, que motiva a ação civil pública 0000.11.2223334 , e responder aos quesitos propostos pelas partes.

\section{2) Partes envolvidas}

AUTOR: Ministério Público do Estado de Minas Gerais, pela Promotoria de Justiça da Comarca de Pequenópolis

RÉU: Fulano de Tal, brasileiro, casado, comerciante, natural de Outro Lugar, Minas Gerais, portador do RG 0.111.222, residente à Rua dos Bobos, número zero, bairro Centro, Pequenópolis, Minas Gerais.

\section{3) Breve relato}

Aos 08 dias do mês de junho de 2017, a Polícia Militar, em atendimento a denúncia anônima, deslocou-se ao local objeto do inquérito, para verificar possível intervenção irregular em Área de Preservação Permanente.

Chegando ao local, constataram as intervenções descritas no REDS 2017-011122222-333, conforme citado em seguida:

"Conforme denúncia via DDU, 181, de nr. $55566677 \mathrm{H}$, acerca de intervenção em área de preservação permanente, fizemos presente à AV. Sanitária, Centro de Pequenópolis, onde constatamos que o Senhor Fulano de Tal, realizou uma intervenção em área de preservação permanente, localizada há menos de 30 metros de curso d'água, mediante a construção de uma edificação, cuja área é estimada em 200 metros quadrados. [...] Adiantovos ainda que o local era descoberto de vegetação nativa, onde não foi realizado nenhuma supressão de vegetação".

$\mathrm{O}$ ato registrado fundamentou o inquérito civil MPMG1111.22.333444-5 movido pela Promotoria de Justiça de Pequenópolis, culminando em ação civil pública, sobre a qual este laudo se presta a esclarecer as questões técnicas pertinentes aos impactos ambientais associados à intervenção relatada.

\section{B. PRESSUPOSTOS, RESSALVAS E FATORES LIMITANTES}

São pressupostos, ressalvas e limitações do presente laudo técnico pericial:

Este trabalho, bem como suas conclusões, é válido apenas nos termos nele expostos, sendo, portanto, vetada sua utilização em conexão com qualquer outro.

Não será assumida responsabilidade, pelo responsável técnico, sobre matéria alheia ao exercício profissional, regido por leis e regulamentos próprios.

\section{METODOLOGIA}

Os métodos utilizados foram:

Vistoria in loco, reportagem fotográfica, aerofotogrametria para obtenção de ortofoto, análise de fotos de satélite, entrevista com o RÉU, coleta de pontos de GPS e análise de documentos.

\section{LOCALIZAÇÃO}

Trata-se de uma área urbana, localizada na Av. José Samartini, bairro Centro, Teixeiras, Minas Gerais.

Coordenadas Geográficas: UTM - Zone 23K; Long. 723457.21m W; Lat. 7715018.545m S.

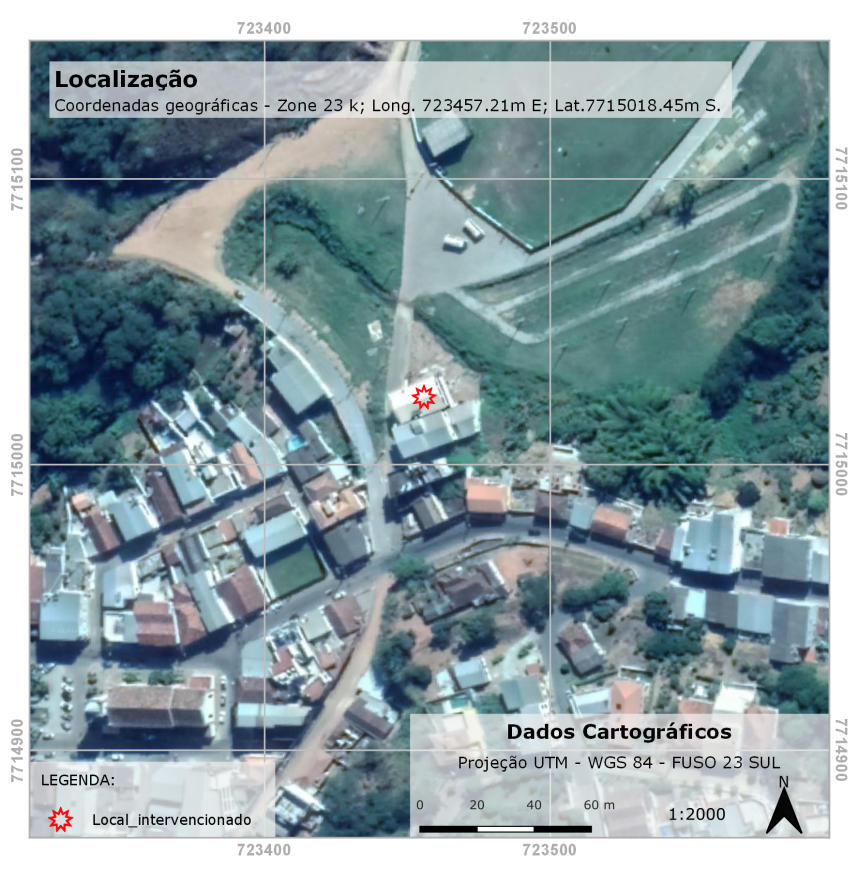

Figura 1. Localização da intervenção urbana Fonte: Imagem de satélite Google Earth Pro em software de geoprocessamento QGis.

\section{E. VISTORIA IN LOCO}

A vistoria do local foi realizada em caráter técnico, buscando identificar os impactos ambientais provenientes da intervenção.

Fora realizada no dia $1^{\circ}$ de outubro de 2019 . Teve início às 08h04min, terminando às $08 \mathrm{~h} 57 \mathrm{~min}$. 
Este perito, e sua equipe técnica, percorram a área intervencionada na presença do RÉU e de seu advogado.

\section{F. CARACTERIZAÇÃO DA ÁREA INTERVENCIONADA \\ 1) Caracterização edáfica}

Trata-se de terreno de topografia ondulada, superfície de solo seco, com classificação pedológica predominante LVAd29, segundo o "Mapa de Solos do Estado de Minas Gerais Legenda Expandida" onde lê-se:

LVAd29 - LATOSSOLO VERMELHO-AMARELO

Distrófico típico, A moderado, textura argilosa/muito argilosa, fase floresta tropical subperenifólia, relevo forte ondulado/montanhoso (50\%) + CAMBISSOLO HÁPLICO Tb Distrófico típico, A moderado, textura argilosa, fase floresta tropical subperenifólia, relevo forte ondulado/montanhoso $(25 \%)+$ ARGISSOLO VERMELHO-AMARELO Distrófico típico, A moderado, textura argilosa/muito argilosa, fase floresta tropical subperenifólia, relevo ondulado.

\section{2) Caracterização biótica}

A área vistoriada está inserida no bioma da Mata Atlântica.

Não possui vegetação nativa.

Foram plantados exemplares de frutíferas exóticas, formando um pomar no espaço remanescente da área original (local indicado para execução de PRAD e PTRF anexos ao processo).

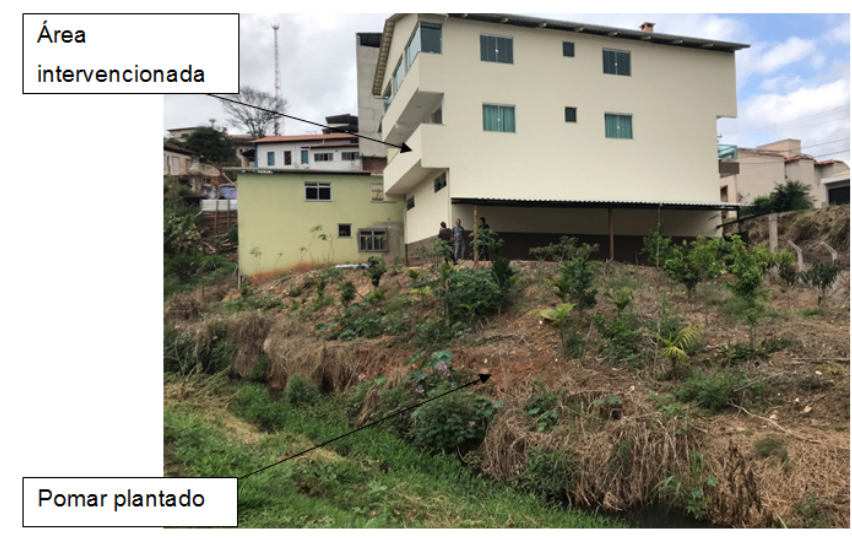

Figura 2. Pomar plantado no remanescente da área. Fonte: arquivo do autor.

\section{3) Caracterização antrópica}

A área em questão está em avançado estado de antropização. Não guarda resquícios de suas características originais.

Os elementos antrópicos associados são: construção de alvenaria, deposição de resíduo sólido, lançamento de efluentes em curso d'água e plantio de espécies exóticas.

\section{G. CARACTERIZAÇÃO DA INTERVENÇÃO}

Construção de um edifício em alvenaria de três pavimentos, em $227,15 \mathrm{~m} 2$. O local intervencionado encontra-se com- pletamente inscrito na faixa marginal de trinta metros a se considerar a calha regular do Córrego Pequeno.

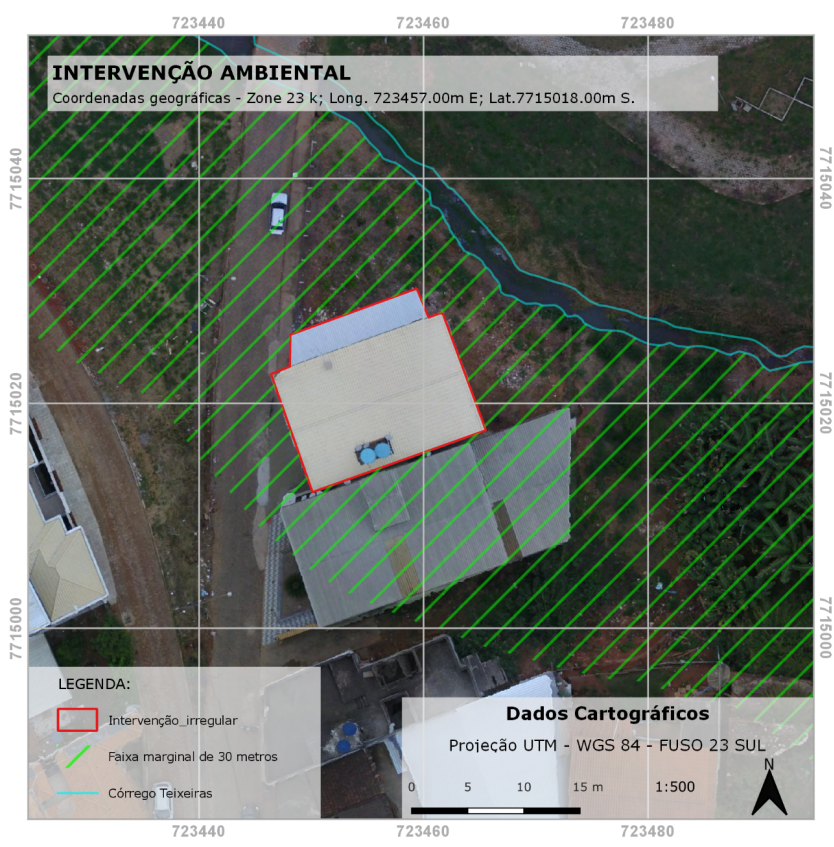

Figura 3. Intervenção ambiental urbana Fonte: Foto aérea, Drone Phanton 3 , data 01/10/2019. Em destaque faixa marginal de 30 metros a se considerar a o leito regular do Córrego Pequeno.

\section{H. COMENTÁRIOS TÉCNICOS}

1) Considerações preliminares

Os trabalhos técnicos periciais identificaram que, de fato, ocorreu a intervenção irregular em área de preservação permanente de curso d'água que motiva a presente ação.

A obra em questão é de responsabilidade do RÉU, Fulado de Tal, atendendo a uma demanda pessoal para prover morada à sua filha.

Pela análise da série histórica de fotos de satélites, disponíveis no software Google Earth Pro, atesto a informação lavrada no Boletim de Ocorrência que acompanha a peça da ação, de que a área era descoberta de vegetação nativa. Entretanto, é necessária a correção de que houve, sim, supressão de vegetação, sendo esta rasteira e, possivelmente, exótica, por não guardar característica semelhante ao que se observa no bioma onde está inserida a área intervencionada.

Necessário se faz compreender a função ambiental à qual a mata ciliar, aqui nos termos da lei definida como área de preservação permanente de curso d'água, se presta. Ela promove proteção ao leito do manancial. Por dificultar o acesso e restringir o contato direto, reduz, consequentemente, o risco de poluição da água. Garante, ainda, um aumento da capacidade absortiva do solo e redução da velocidade das águas de chuva, mitigando, assim, o risco de erosão superficial e o assoreamento do curso d'água.

Quanto à autorização formal para execução da obra, esta não foi expedida nem pela prefeitura, por meio de alvará 


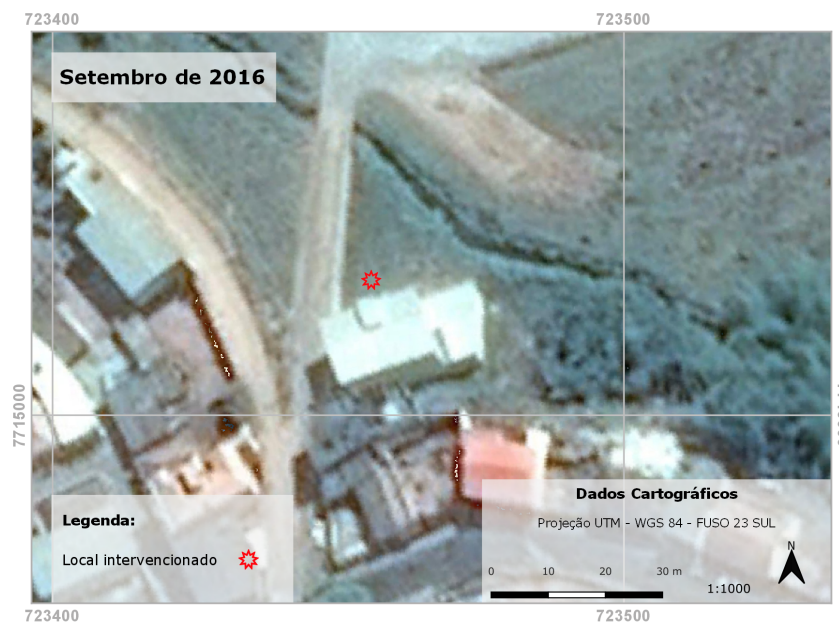

Figura 4. Foto história setembro 2016 Fonte: arquivo do autor. Destaque para área intervencionada, antes do início da intervenção. Não se observa presença de vegetação nativa característica do bioma da Mata Atlântica. Fonte: Googe Earth Pro, data 18/09/2016.

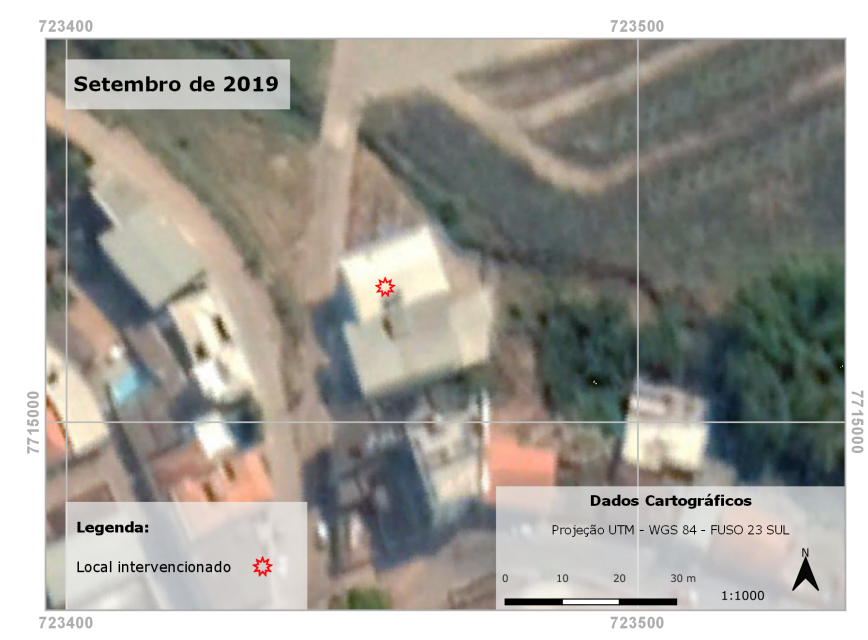

Figura 5. Foto histórica setembro 2019 Descrição: Destaque para área intervencionada, após estabelecida a intervenção. Houve a supressão da vegetação rasteira que recobria toda a extensão da área. Fonte: Google Earth Pro, data 08/07/2018.

de construção ou documento semelhante, nem pelo órgão ambiental competente.

Há, ainda, que se considerar que, por tratar-se de uma morada, os impactos ambientais provenientes da intervenção não se restringem somente ao fato da construção, mas englobam, também, os impactos inerentes à vida humana.

\section{2) Impactos ambientais associados}

A avaliação dos impactos ambientais advindos da intervenção periciada foi realizada por meio do preenchimento de uma Matriz de Avaliação de Impactos Ambientais - MAIA apresentada no ANEXO 1.

A essa altura, é necessário o pleno entendimento de que a intervenção inicial é a construção irregular; entretanto, o seu uso para moradia, gera impactos ambientais.
Dessa forma, temos duas etapas de intervenção, sendo elas: construção e habitação.

Da etapa de construção, o aspecto ambiental (ou elemento da atividade) correlato é a própria locação da obra, que, por meio da supressão de vegetação, do preparo da fundação e da execução da obra, gera como impactos ambientais (modificações no ambiente) aumento da velocidade de escoamento superficial da água de chuva, impermeabilização do solo e alteração da paisagem local.

Todos os três impactos associados à etapa de construção apresentam características semelhantes, sendo classificados como: permanentes quanto à duração, pois seus efeitos continuam a serem observados, mesmo se interrompida a atividade; pontuais, pois expressam influência somente na área diretamente afetada; de baixa magnitude, quanto à intensidade da alteração promovida, devido ao tamanho da intervenção; negativos, pois causam prejuízo à função ambiental da área; e irreversíveis, pois ações de controle podem gerar impactos de maior relevância.

Considerando o produto dos critérios avaliados, e que os impactos até aqui descritos causam influência na área diretamente afetada pela obra, avalio os impactos ambientais advindos da etapa de construção em sendo negativos de baixa relevância.

Da etapa de habitação, o aspecto ambiental correlato é a produção de resíduos que, por meio da deposição de resíduos sólidos e lançamento de efluentes no curso d'água, podem causar, como impacto, a degradação ambiental.

Com relação aos critérios avaliados, este impacto é classificado como: temporário quanto a duração, pois se interrompida a atividade, seus efeitos desaparecem com o tempo; local, pois expressa influência que extrapola os limites da área diretamente afetada, incidindo o impacto na área de influência direta; de alta magnitude, pois apesar do baixo volume produzido, o efluente doméstico está sendo lançado diretamente no curso d'água; negativo, pois causa prejuízo à função ambiental da área; e reversível, pois pode ser controlado com a interrupção do lançamento dos efluentes.

Considerando o produto dos critérios avaliados, e que o impacto descrito tem efeitos na área de influência direta, avalio o impacto advindo da etapa de habitação, em sendo, negativo de baixa relevância.

Nesta altura, vale a ressalva de que, independentemente do nível de relevância, todo impacto ambiental negativo deve ser mitigado ou compensando, pois causa ou causou prejuízo à função ambiental do local influenciado por seus efeitos

\section{3) Medidas técnicas a serem adotadas}

As medidas técnicas que serão propostas visam interromper o avanço, mitigar e compensar os impactos provenientes da intervenção irregular, além de reabilitar o local.

Considerando que a área intervencionada está inscrita em APP de curso d'água, ela teria a função ambiental de proteção do manancial, conforme descrito nos comentários preliminares. Entretanto, observo que o avançado processo de antropização do local e da circunvizinhança, antes mesmo do 
início da intervenção, reduziu, drasticamente, essa característica protetiva a qual a área se prestava e, consequentemente, restringiu sua função ambiental.

Buscando, um maior ganho ao meio ambiente, a melhor alternativa técnica seria abster-se de esforços em recuperação direta da área intervencionada, empenhando-se, porém, em sua reabilitação. Os impactos associados diretamente à construção serão compensados em outra área, dentro da mesma bacia hidrográfica, com função ambiental similar, a dispêndio do RÉU.

Ainda neste sentido, atesto inviabilidade técnica em demolição da obra, pois essa ação causaria impactos ambientais com maior relevância que a intervenção em si, como, por exemplo, a deposição dos entulhos produzidos causaria a alteração de características físicas e químicas do solo onde fosse depositado. Sendo avaliado como impacto negativo de relevância média.

Para reabilitação da área intervencionada, deve-se proceder o fechamento com cerca e recuperação de uma faixa marginal de cinco metros a partir da calha regular do Córrego Teixeiras, conforme projeto técnico anexo. Deve-se interromper o lançamento de efluentes domésticos no curso d'água, por meio de apresentação de projeto técnico e construção de fossa séptica segundo os termos da NBR7.229 e NBR13.969.

Como já apresentado anteriormente no corpo do presente laudo, os impactos ambientais provenientes da intervenção, perdurarão no tempo em que a obra se fizer presente e habitada. Atestou-se ainda, a inviabilidade da remoção da intervenção por meio de demolição. Definiu-se como sendo necessária a compensação dos impactos associados.

Considerando que a vida útil de um imóvel urbano, por convenção, é de 50 anos e que a intervenção se deu em 227,15 $\mathrm{m} 2$, como forma de compensação ambiental pelos impactos pretéritos e futuros, o RÉU deverá garantir a preservação de uma área total igual a uma vez a área intervencionada para cada ano de vida útil do imóvel construído, ou ainda, $11.357,5 \mathrm{~m} 2$ (1,13hectares).

Em entrevista com o RÉU, ele sinalizou ser proprietário de um imóvel rural no município de Pequenópolis. Após solicitado, foi apresentado ao perito o Recibo de Inscrição do Imóvel Rural no CAR, bem como a certidão de inteiro teor do imóvel, estando este registrado sob matrícula 1111Livro02, no Cartório de Registro de Imóveis dessa Comarca. Ambos os documentos estão anexos ao presente laudo.

A compensação ambiental deverá ser conduzida no imóvel descrito acima. A alocação da área e definição das técnicas envolvidas no processo, serão estabelecidas após vistoria local, em laudo complementar.

\section{RESPOSTA AOS QUESITOS}

1) Quesitos do autor

\section{- Houve intervenção em APP? Especificar.}

Sim. Houve intervenção ambiental não autorizada a menos de trinta metros da calha regular do Córrego Teixeiras, que apresenta largura média de dois metros no local.

- A APP em questão é rural ou urbana?

Trata-se de área de preservação permanente urbana .

- Quem é o responsável pela intervenção?

O responsável pela intervenção é o senhor Fulano de Tal.

- Descrever as eventuais intervenções realizadas na APP.

As intervenções realizadas na APP foram: construção de obra em alvenaria e lançamento de efluentes em curso d'água natural.

- Qual a finalidade da intervenção?

A intervenção foi realizada com a finalidade de moradia.

- A intervenção se enquadra em algum dos casos excepcionais previsto na legislação? Especificar.

A perícia judicial é realizada em caráter puramente técnico, não cabendo ao perito emitir parecer judicial.

- Houve licença/autorização do órgão ambiental para a intervenção?

Não houve licença ou autorização de nenhum órgão ambiental para que tal intervenção ocorresse.

- O empreendimento propicia risco ou agravamento de processos como enchentes, erosão etc.?

Primeiramente, vale ressaltar que os processos de enchente e erosão são fruto do aumento da velocidade de escoamento superficial, somado à redução na capacidade de infiltração da água de chuva. Dessa forma, a intervenção em questão não propicia risco, pois, apesar de promover os impactos descritos acima, sua dimensão relativamente pequena, não seria capaz de promover, por si só, esses eventos. Entretanto propicia agravo, uma vez que, inserida no cenário macro da zona urbana, passa a compor uma área com características semelhantes entre elas, e que, estas sim somadas, podem vir a causar tanto enchentes quanto erosão, devido à redução da taxa de infiltração e aumento da velocidade de escoamento superficial da água.

- Descrever medidas compensatórias a serema adotadas pelo empreendedor como reparação do dano causado.

Como forma de reabilitar a área intervencionada, o RÉU deverá cercar a faixa marginal do Córrego Teixeias em cinco metros dentro de seu terreno e realizar o plantio de espécies nativas conforme descrito no projeto técnico anexo. Ainda na área intervencionada, deverá custear projeto e execução de uma fossa séptica segundo as normativas NBR 7.229 e NBR 13.969, interrompendo o lançamento de efluentes no curso d'água. Como forma 
de compensação dos impactos ambientais pretéritos e futuros advindos da intervenção em questão, o RÉU deverá conduzir a recuperação ambiental em uma área de 1,13 hectares em sua propriedade rural, situada no município de Teixeiras. A alocação da área e definição das técnicas envolvidas no processo, serão estabelecidas após vistoria local, em laudo complementar.

- Tecer outras considerações eventualmente necessárias.

Nada mais a declarar no momento.

\section{2) Quesitos do réu}

- Pode o Sr. Perito informar se a permanência do imóvel no local onde está causará ou causou algum dano ambiental significativo?

Por se tratar de moradia, o imóvel causou impactos ambientais associados à sua construção e permanecerá, no tempo, causando impactos, provenientes de sua ocupação, sendo estes classificados como negativos de baixa relevância, conforme descrito na matriz de impactos ambientais apresentada no corpo deste trabalho.

- Pode o Sr. Perito informar se, caso tenha havido algum dano, se este é considerado de Baixo Impacto? Os impactos advindos da intervenção são negativos de baixa relevância.

- Pode o Sr. Perito informar se a Deliberação Normativa 226 do COPAM de 25 de julho de 2018 pode ser aplicada neste caso? Haja visto o Artigo $1^{\circ}$ e inciso IX?

Reitero que a perícia judicial é realizada em caráter puramente técnico, não cabendo ao perito emitir parecer judicial.

No intuito de auxiliar o bom andamento da justiça esclareço que o imóvel está inserido na zona urbana, onde disfruta de acesso pavimentado, iluminação pública, abastecimento de água e energia elétrica, não possui solução para esgotamento sanitário ou de águas pluviais, uma vez que esta é feita diretamente no curso d'água. Não cabe, ainda, a este perito discorrer quanto à regularidade do parcelamento do solo onde se encontra a intervenção, por não ser este o objeto do presente trabalho.

- Pode o Sr. Perito informar se caso se decida pela retirada do imóvel ( 2 moradias) se esta ação causará mais danos do que a permanência da mesma no local?

A retirada do imóvel por meio de demolição causaria impacto ambiental de maior relevância que a manutenção dele no local.

- Pode o Sr. Perito descrever sobre a relação de au- mento dos danos ambientais ocorridos entre o início do fato danoso, conforme os autos, para os dias atuais?

Os primeiros impactos ambientais associados à construção irregular estão diretamente relacionados ao manejo das águas de chuva, devido a supressão de vegetação rasteira e impermeabilização do solo por meio da construção, propriamente dita. O outro impacto seria a alteração da paisagem local. Estamos tratando de impactos negativos, pontuais, de baixa magnitude, permanentes e irreversíveis (desde que não haja demolição). Com a habitação da construção, o aspecto ambiental ganha caráter temporal, pois enquanto habitado, a intervenção passa a gerar os impactos intimamente ligados à vida humana.

- Pode o Sr. Perito informar se a intervenção promovida pelo réu com a manutenção da estrada vicinal se pareceu benéfica ou não resolveu o problema?

Não cabe resposta ao quesito, por não ter correlação com o caso avaliado pelo presente trabalho pericial. (COMENTÁRIO DO AUTOR: o advogado do réu confirmou que o presente quesito foi enviado por equívoco, não havendo correlação com o caso analisado pela perícia. Apresento ele como forma de ilustrar as diferentes situações do cotidiano pericial).

- Pode o Sr. Perito informar se a permanência do imóvel no local referido acarretará problemas para a questão hídrica (curso de água que passa próximo) ou interferirá no seu curso normal?

A permanência do imóvel, em si, não acarretará problemas para a questão hídrica. Entretanto, por se tratar de casa morada, se não aplicadas as devidas medidas mitigadoras, como o correto destino dos efluentes domésticos por meio da construção de uma fossa e o isolamento e recuperação da margem em cinco metros, os impactos ambientais inerentes à vida humana serão persistentes enquanto o imóvel for habitado, podendo, sim, acarretar problemas para a questão hídrica como a poluição do corpo d'água.

- Pode o Sr. Perito Informar se as medidas técnicas apontadas no PRTR e Plano Técnico apresentados mitigarão as intervenções realizadas?

Certamente mitigam parte dos impactos associados à intervenção, por se tratar de aspecto ambiental com impacto positivo, não sendo suficientes, entretanto, para compensar os prejuízos ambientais.

- Pode o Sr. Perito informar se houve comprometimento significativo de áreas de preservação ambiental advindo da implantação destas moradias, ou podemos considerar as mesmas de baixo impacto? A Área de Preservação Permanente onde a intervenção está inserida já estava significativamente comprome- 
tida antes mesmo da ocorrência desta. A construção irregular, passa a compor mais um aspecto no leque de comprometimentos que assolam o local. Os novos impactos advindos da intervenção são negativos com baixa relevância, conforme ilustra a MAIA anexa.

- Pode o Sr. Perito informar se houve intervenção direta em leito de curso d'água situado no local em tela?

Houve intervenção direta em leito de curso d'água com a descarga de efluentes domésticos e águas pluviais, conforme demonstra reportagem fotográfica apresentada em anexo.

- Pode o Sr. Perito relacionar todos os impactos diretos e indiretos causados ao meio físico (solo, subsolo, águas superficiais, águas subterrâneas, características geomorfológicas, hidrogeológicas e ambientais) em decorrência dos fatos?

Os impactos ambientais são: impermeabilização do solo, aumento da velocidade de escoamento superficial de água de chuva, alteração da paisagem e degradação ambiental.

- Pode o Sr. Perito esclarecer se a área de intervenção é considerada de preservação permanente, especificando as hipóteses legais em que a mesma se enquadra, conforme Código Florestal Brasileiro e Mineiro? E descrever ser a DN226 citada no quesito 3 se aplica a este caso?

Novamente, a perícia judicial é realizada em caráter puramente técnico, não cabendo ao perito emitir parecer judicial.

\section{J. ANEXOS}

ANEXO I - Matriz de Avaliação de Impacto Ambiental;

ANEXO II - Recomendações técnicas de cercamento e recuperação de faixa marginal de curso d'água;

ANEXO III - Galeria de fotos;

ANEXO IV - Documentos.

\section{K. CONCLUSÕES}

Com base no trabalho realizado, conclui-se que;

- Houve a construção de um edifício em alvenaria de três pavimentos em $227,15 \mathrm{~m} 2$, totalmente inserido na faixa marginal de trinta metros a contar da calha regular do Córrego Pequeno;

- Não houve autorização para construção por parte da prefeitura, ou do órgão ambiental competente;

- intervenção se dá em duas etapas: construção e habitação;

- Os impactos associados à etapa da construção são: impermeabilização do solo, alteração da paisagem e aumento da velocidade de escoamento superficial da água de chuva, por meio da supressão de vegetação e execução da obra;

- O impacto associado à etapa de habitação é: degradação, por meio do depósito de resíduos sólidos e lançamento de efluentes domésticos em curso d'água;

- Os impactos ambientais foram avaliados como negativos de baixa relevância;

- As medidas técnicas a serem adotadas para reabilitação da área intervencionada são: isolamento e recuperação da faixa marginal em cinco metros por toda a extensão do terreno do RÉU; projeto e execução de fossa séptica para dar destino correto aos efluentes domésticos; interromper o lançamento de efluentes no curso d'água;

- As medidas técnicas a serem adotadas para compensação dos impactos pretéritos e futuros, frutos da intervenção irregular, são: conduzir recuperação ambiental em área de 1,13ha, em terreno rural de propriedade do RÉU;

- A alocação da área e definição das técnicas envolvidas no processo de recuperação ambiental, serão estabelecidas após vistoria local, em laudo complementar.

\section{TERMO DE ENCERRAMENTO}

Encerra-se o presente Laudo composto de X (indica quantas páginas sem contar capa e sumário) páginas impressas em anverso, numeradas no canto inferior direito, todas rubricadas, sendo a última datada e assinada e 4 anexos.

Na oportunidade, este perito agradece a Meritíssima Juíza a confiança depositada no ato da nomeação, e prontifica-se a prestar os esclarecimentos que se fizerem necessários.

Viçosa, 28 de outubro de 2019.

\section{Hugo Frederico Sickert de Almeida Rocha PERITO JUDICIAL \\ Eng. Agrônomo - CREA-GO 1015068677/D}

\section{ANEXO I MATRIZ DE AVALIAÇÃO DE IMPACTO AMBIENTAL MAIA}

1) Objetivo

Avaliar os impactos ambientais provenientes de intervenção ambiental, que motiva a ação civil pública 0000.11.2223334.

\section{2) Maia}

A tabela 1 apresenta a Matriz de Avaliação de Impactos Ambientais.

\section{3) Metodologia}

Identificação e listagem das etapas da intervenção, dos aspectos ambientais e dos impactos a eles associados. Para cada impacto são atribuídas notas, segundo pesos específicos de cada critério a ser avaliado.

De posse das notas, é calculado o produto delas (para cada impacto).

Esse valor é então correlacionado com a unidade espacial onde o impacto gera seus efeitos, para definir sua relevância 
Tabela 1. Matriz de Avaliação de Impactos Ambientais.

\begin{tabular}{|c|c|c|c|c|c|c|c|c|c|c|}
\hline \multicolumn{11}{|c|}{ MA TRIZ DE AVALIAÇÄO DE IMPACTOS AMBIENTAIS } \\
\hline & \multicolumn{2}{|c|}{ ASPECTO COM INTERFACE AMBIENTAL } & \multirow[b]{2}{*}{ IMPACTO AMBIENTAL } & \multicolumn{6}{|c|}{\begin{tabular}{|l} 
CRITÉRIOS DE AVALIAÇÄO \\
\end{tabular}} & \multirow[b]{2}{*}{ REL } \\
\hline $\begin{array}{l}\text { ETAPA DA } \\
\text { INTERVENÇÄO }\end{array}$ & IDENTIFICAÇÄO & ORIGEM & & DUR & $\mathrm{AE}$ & MAG & REV & Prod. & RFL & \\
\hline \multirow[b]{3}{*}{ Construçạ̈ } & \multirow{3}{*}{$\begin{array}{l}\text { Locaçāo da } \\
\text { constinuçä̉ }\end{array}$} & \multirow{2}{*}{ Execuçäo da oba } & InpeameabT zaçäo do solo & 2 & 1 & 1 & 2 & 4 & - & Baixa \\
\hline & & & Aleraçäo da paisagem & 2 & 1 & 1 & 2 & 4 & - & Baixa \\
\hline & & Supressīo da vegetaçäo & $\begin{array}{l}\text { Aumeato da velocidade de } \\
\text { escoamento supeaficial da água de } \\
\text { chuwa }\end{array}$ & 2 & 1 & 1 & 2 & 4 & - & Baixa \\
\hline \multirow[b]{2}{*}{ Habilaçäo } & \multirow{2}{*}{$\begin{array}{l}\text { Phoduçāo de } \\
\text { Iesiduos }\end{array}$} & Deposiçāo de residhoos sítidos & Degradaçäo ambiental & 1 & 1 & 1 & 1 & 1 & - & Desprezive: \\
\hline & & $\begin{array}{l}\text { Lançamento de eluente doméstico } \\
\text { en cuso dạ́̀ua }\end{array}$ & Degradaçäo ambiental & 1 & 2 & 3 & 1 & 6 & - & Baixa \\
\hline \multirow{4}{*}{ Demolição } & \multirow{4}{*}{$\begin{array}{l}\text { Retirada da } \\
\text { construção }\end{array}$} & \multirow{2}{*}{$\begin{array}{c}\text { Uso de caminhões e máquinas } \\
\text { pesadas }\end{array}$} & Poluição do ar & 1 & 2 & 1 & 1 & 2 & - & Baixa \\
\hline & & & Poluição sonora & 1 & 1 & 1 & 1 & 1 & - & Desprezível \\
\hline & & \multirow[b]{2}{*}{ Deposição de resíduos sólidos } & Alteração da paisagem & 2 & 1 & 1 & 2 & 4 & + & Baixa \\
\hline & & & \begin{tabular}{|c|}
$\begin{array}{c}\text { Alteração de características fisicas } \\
\text { e químicas do solo onde } \\
\text { depositado }\end{array}$ \\
\end{tabular} & 2 & 1 & 2 & 2 & 8 & - & Média \\
\hline
\end{tabular}

4) Descrição dos critérios e respectivos pesos

- Duração (DUR) - Faz referência à duração dos efeitos advindos de um determinado impacto ambiental. São classificados como: temporário (peso 1), quando os seus efeitos são observados durante a ocorrência da atividade geradora de impacto, ou no curto espaço de tempo após cessada a ação; ou permanente (peso 2), quando os efeitos são observados mesmo após o encerramento da atividade, sem possibilidade de ser naturalmente revertido no curto espaço de tempo.

- Abrangência espacial (AE) - Classifica o impacto quanto ao alcance dos efeitos dele, sendo: pontual (peso 1) quando o incide somente na área diretamente afetada (ADA); local (peso 2) quando incide na área de influência direta (AID); ou regional (peso 3) quando extrapola a área de influência direta, atingindo a área de influência indireta (AII).

- Magnitude (MAG) - Refere-se à intensidade da alteração promovida no ambiente pelo impacto, sendo classificada como: baixa (peso 1), média (peso 2) ou alta (peso3).

- Reversibilidade (REV) - reversível (peso 1) quando o impacto pode ser controlado de forma eficiente sem que haja prejuízo ambiental no processo e irreversível (peso 2) quando o impacto não pode ser controlado ou seu controle demande ações que trarão prejuízos ambientais superiores aos a ele associados.

- Reflexo (RFL) - positivo (+) quando tratar de impacto que gere ganho ambiental e negativo (-) quando gera prejuízo ambiental.

\section{5) Tabela de referências}

A tabela 2 é utilizada para definir a relevância dos impactos ambientais.
Tabela 2. Tabela de relevância

\begin{tabular}{|c|c|c|c|c|}
\multicolumn{1}{c|}{} & \multicolumn{4}{|c|}{ Relevância } \\
\hline $\begin{array}{c}\text { Unidade } \\
\text { espacial }\end{array}$ & Desprezível & Baixa & Média & Alta \\
\hline $\begin{array}{c}\text { Área } \\
\text { diretamente } \\
\text { afetada }\end{array}$ & $1-3$ & $4-6$ & $7-9$ & $8-12$ \\
\hline $\begin{array}{c}\text { Área de } \\
\text { iffluência } \\
\text { direta }\end{array}$ & $2-6$ & $7-12$ & $13-18$ & $18-24$ \\
\hline $\begin{array}{c}\text { Área de } \\
\text { influência } \\
\text { indireta }\end{array}$ & $3-10$ & $11-18$ & $19-26$ & $27-36$ \\
\hline
\end{tabular}

\section{CONCLUSÕES}

A perícia ambiental cumpre seu papel de fornecer embasamento técnico para as decisões judiciais. Sem este trabalho, faltariam amarrações formais que justificassem os julgamentos por parte dos magistrados, podendo eles incorrerem ao erro.

Nas páginas que passaram foram apresentadas situações reais do cotidiano de um perito ambiental, bem como as formas como este profissional lidou com elas.

Todas as medidas técnicas apresentadas foram acatadas e estão sendo executadas, com a finalidade máxima de buscar um reestabelecimento do equilíbrio entre a degradação que foi praticada e os benefícios ambientais possíveis advindos das ações propostas.

\section{Referências}

[1] BRASIL. Lei no 6.938 de 31 de agosto de 1981. Dispõe sobre a Política Nacional do Meio Ambiente. Diário Oficial da República Federativa do Brasil, Brasília, DF, 02 set.1981.

[2] BRASIL. Lei $n^{\circ} 12.651$, de 25 de maio de 2012. Dispõe sobre a proteção da vegetação nativa. Diário Oficial da República Federativa do Brasil, Brasília, DF, 28 mai. 2012. 
[3] FEAM. Mapa de Solos do Estado de Minas Gerais. Disponível em http://www.feam.br/images/stories/arquivos/mapadosolo/mapa_solos_4.jpg.Acesso em 05 de junho de 2020.

[4] SEMAD. Mapa de Solos do Estado de Minas Gerais Legenda Expandida. Disponível em https://www.yumpu.com/pt/document/view/13517989/mapa-de-solos-doestado-de-minas-gerais-legenda-expandida. Acesso em 05 de junho de 2020.

[5] Silva, José de Castro. Código Florestal: uma visão técnica e jurídica - 1 ed. - São Paulo: Braúna, 2016. 826p.

[6] Manual prático para montagem de cercas - Gerdau. Disponível em https://www.gerdau.com/br/pt/productsservices/products/Document\%20Gallery/manual-cercas.pdf Acesso em 05 de abril de 2019.

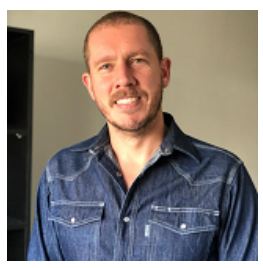

HUGO FREDERICO SICKERT DE ALMEIDA ROCHA

Engenheiro Agrônomo pela Universidade Federal de Viçosa - UFV, Especialista em Perícia e Auditoria Ambiental pela Univiçosa, perito cadastrado no banco de Auxiliares da Justiça do Tribunal de Justiça do Estado de Minas Gerais e na Central de Apoio Técnico do Ministério Público do Estado de Minas Gerais.

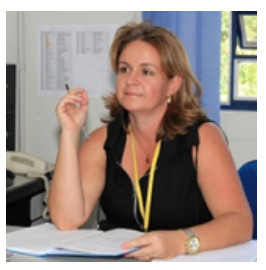

CRISTIANE PIRES SAMPAIO

Graduada em Engenharia Agrícola pela Universidade Federal de Lavras (1997), Mestrado (2000) e Doutorado (2004) em Pré-processamento de Produtos Agrícolas pela Universidade Federal de Viçosa. Atuou como coordenadora de Projeto (Jan/2005 a Jul/07) vinculado ao Programa de Desenvolvimento Científico Regional do estado do Tocantins, em Palmas. Concluiu o Pós-Doutorado Júnior em Biocombustíveis pela Fapemig, atuando na Unidade Regional da Zona da Mata-Epamig. Há 8 anos é gestora do Curso Superior de Tecnologia em Gestão Ambiental. Foi também coordenadora do MBA em Análise e Gestão Ambiental da Faculdade de Ciências Biológicas e da Saúde FACISA (2010-2016). Atualmente coordena o curso de pós-graduação em "Perícia e Auditoria Ambiental e atua como docente em vários cursos da IES. 